\title{
Analysis on Vocabulary Application Between English Major and Non-English Major Students
}

\begin{abstract}
ZHENG Ling
Changchun University, Changchun, China

English vocabulary learning has always been a problem for Chinese students. To this, the author makes a research on vocabulary application between English major and non-English major students through the part of the investigation and analysis about English major and non-English major students' vocabulary application situation, including: (1) Both English majors and non-English majors of Chinese students adopt some strategies and methods in their process of learning and remembering new words, but the effect of the non-English major students is not good in common; and (2) Two groups of students have an obvious difference in vocabulary learning strategies, and the main cause of the difference is their concepts of vocabulary learning and the different curricula. All the findings above show the effective learning strategies in English vocabulary learning are of great importance. The author hopes this article will get some revelations to the university public English vocabulary teaching, and to help non-English major students' vocabulary application.
\end{abstract}

Keywords: vocabulary application, strategy, differences

\section{Introduction}

Vocabulary learning is a very basic part of the process of English as a Foreign Language (EFL). The emphasis in college English stage should be to expand the reading quantity and train the ability of practical application, which is to be on the premise of vocabulary expansion. As the experts say: "Grammar provides the overall patterns, vocabulary, the material to put in the pattern" (Cook, 1998), the main task of the college students is to accumulate raw materials - words. Thus, how to effectively get and save the phrasing of raw materials is the key. But the fact is that many Chinese non-English major students have the problem of remembering and applying new words to a certain extent. Many scholars have found through making research on English vocabulary learning strategies of non-English major students that they will consciously adopt certain skills when learning words, but the strategies they used are improper. Therefore, the author designs the study to find good vocabulary application strategies for English majors and non-English major students through further study.

\section{The Research Method}

\section{Research Content}

This research project mainly wants to answer the following questions:

ZHENG Ling, lecturer, master, Foreign Languages College, Changchun University. 
(1) Which is adopted in English vocabulary learning strategies and methods for Chinese students?

(2) What is the difference on the strategy used between English majors and non-English majors?

(3) What is the cause of these differences?

(4) What enlightenment does the results of the study have to college English teaching and learning practice?

\section{Study Object}

The 20 grade three non-English major objects in this investigation come from different professional. Because after more than two years of learning, examination, and practice, they have formed a relatively mature and fixed English study view and method, and have been more clear of their own problems and learning characteristics. Most of them have passed College English Test Band 4 (CET-4), but only half of the students are one-time pass. At the same time, a lot of students who are preparing for the College English Test Band 6 (CET-6) spend most of the time in dealing with vocabulary learning, but the effect is not ideal. The author contacts 10 grade four students for English majors with the help of friends, who all have got the English Test for English Majors-Band 8 (Tem- 8$)$ certificate. At the same time, their vocabulary at least has between 8,000-12,000 according to the professional requirements. Though it is not comparable between these two majors, the test objects, test property, and test object are completely different, but the learning way can be as reference. The specific information is as follow (see Table 1):

Table 1

Information of Respondent

\begin{tabular}{|c|c|c|}
\hline \multicolumn{3}{|c|}{ Survey object } \\
\hline \multirow{2}{*}{ Major } & \multirow{2}{*}{ English } & Non-English \\
\hline & & Clinical medicine (5), nursing (5), health information (5), emergency (5) \\
\hline Grade & 4 & 3 \\
\hline Sex & Male (3), Female (7) & Male (10), Female (10) \\
\hline
\end{tabular}

\section{Specific Way}

In June 2015, the author makes a directly face to face interview on the object of the questionnaire as shown in the following content, and also has a 10 minutes' conversation with each student. At last, the author makes detailed records, organizes and analyzes carefully. Although it spends more time, people can understand the details, and make an explanation immediately when there are any questions or misunderstandings.

\section{The Results and Analysis}

\section{Results Review}

This paper divides the two groups of students into five aspects according to the results of interviews about English vocabulary learning strategies.

\section{Vocabulary Sources}

Students will encounter a number of new words everyday, and it is unable for them to memorize them all, so they have to make a choice, decide which word to learn and what extent to reach.

According to the talk with 10 English major students, they think it is necessary to carefully study most of the words and phrases in textbooks. Careful study means that students need to be familiar with all aspects of a word, 
such as pronunciation, spelling, parts of speech, collocation, and so on. As for other new words they meet in the extensive reading course and newspaper reading, they will choose to learn those which have higher frequency or interest them. In addition, they also focus on recent popular or popular new words and views.

Most of the 20 non-English major students make a variety of vocabulary book as their main source of vocabulary learning, but the manual only provides basic vocabulary pronunciation and simple Chinese annotation, without making detailed annotations and examples. In this case, students learn each word basically in the same way—remembering spelling, practicing pronunciation, and learning Chinese explanation. Sometimes, they put the paper record access to some of the new words in reading comprehension. Only three people have the habit of reading English newspaper or novel.

\section{The Use of Dictionary}

A dictionary is an essential tool in vocabulary learning. From the perspective of the investigation result, whether English major or not, all students use the dictionary, but there is a larger difference in the choice of the dictionary, and how to use a dictionary.

Ten English major students tend to use English-English dictionary in learning; they also use the English-Chinese dictionary of course, but they think that to learn a foreign language with native language vocabulary is more than just to remember a corresponding word, but to fully understand the situation of using the word or context collocation relations. Not all the English words can find the corresponding word in Chinese. English-Chinese dictionary can only provide the most close Chinese interpretation, but is unable to provide the original and specific explanation. While the English-English dictionary can provide a more specific and definite cultural background or the interpretation of usage scene. Thus, English learners can distinguish the difference between synonyms according to the specific English interpretation, and put them in the right expression.

The non-English major group is just the opposite. They rely mainly on the English-Chinese dictionary, and even students use only simple vocabulary as a dictionary. They look up words only to see Chinese explanation, rarely to spend time in experiencing the examples.

\section{The Implementation of the Rote-Learning}

Rote learning is the process of memorizing by repetition, without understanding the knowledge remembered, but its effect is ideal. English major students do not reject the learning methods of "mechanical memorizing". They also adopt the way of reciting in order to rapidly increase their vocabulary in a short time in the initial stage of English learning. And the vocabulary memory method is different when language knowledge accumulation to a certain degree. Rote-learning is mainly used to memorize some terms, name, etc.

The dependent non-English major group of "cramming" is relatively high. When it comes to the preparation for CET-4 and CET-6, most of the students take the method of memorizing words, namely buying all kinds of vocabulary books every day to recite a batch in alphabetical order. They do not go to understand the words usage and difference, because the exam scores of objective questions generally only need to be understood, and students need not to spell words and sentences.

\section{Words Use}

Both the two groups of students surveyed say that the actual use is the best way to grasp the vocabulary and phrases. English major students say they have a lot of opportunities to use the new words, writing; translation, 
theatrical performances, and classroom discussion are the best occasions to try to express what they have learned. Especially in the writing and translation practice, students can have a further understanding in the process of involved vocabularies finding, comparison, and selection. Compared to English majors, non-English major students have less chance to use English a lot. In addition to the difference of curriculum itself, the student are also afraid to speak English. It is common among them to be lack of confidence and afraid of being laughed when they have made mistakes. If necessary, they would rather try to choose simple words and expressions to avoid mistakes; this tendency is particularly apparent in the writing test. Even some teachers will encourage this to deal with the exam.

\section{The Factors Causing the Differences}

\section{Difference in Vocabulary View}

When asked about the importance of vocabulary learning in English learning, all the students think it is the primary task of English course, even more important than grammar. But there is a deviation of non-English major students' vocabulary nature: They only focus on the process of learning and neglect the actual use. They will ask English major secret for the secret of remembering so many words, because in their view, English major have a large number of words, and vocabulary size is the only difference between English major and non-English major students. Actually, English major is not alone the partition for vocabulary learning, they are just mastering the vocabulary combined with other aspects of English learning.

\section{Different Learning Goals}

Non-English major students say the biggest purpose of accumulating vocabulary for them is to pass the CET-4 and CET-6 test. They think they can better solve the part of reading and listening in the test with more vocabularies. On the premise of targeted examination, they concern more about the Chinese interpretation of words and grammar rather than their specific usage and background, so that they may know many words that cannot be used correctly in communication.

The main purpose of expanding the vocabulary for English major is to better use the language. With the expanding of their vocabulary, they can read more information and write articles with more vivid words. For them, the exam is just the tool testing whether they have made progress in a certain period of time.

\section{Conclusion}

\section{Main Findings}

The vocabulary application for English majors is diverse; they make actual practice of vocabulary through class discussion, writing, watching movies, drama, debate, and other forms. Non-English major students' vocabulary application method is unitary; the dictionary back word is their main task; and their biggest problem is the lack of practice opportunities, which hinders the fluency of their expressing ideas in English.

English major students study vocabulary not only for examination, but apply them to practice of various kinds of occasions consciously after learning, while non-English major students study vocabulary mainly because of the test pressure.

English major students know use different strategies in different stages of learning and different vocabulary, but non-English major students is not strong in the aspects of consciousness. 


\section{Enlightenment}

The difference of English vocabulary application between English major and non-English major is as follows.

Non-English major students, by contrast to the English major students, find their own shortcomings, especially in the use of the dictionary and practice to improve.

College English teachers should spend more time trying to introduce students to some of the vocabulary application strategies and the background knowledge of linguistics, and give students more chances to practice improving their self-confidence in English vocabulary learning.

\section{References}

Carter, R. (1987). Vocabulary: Applied linguistic perspective. London: Allen \& Unwin.

Cook, V. (1998). Second language learning and language teaching. Beijing: Foreign Language Teaching and Research Press.

WANG, L. Y. (2001). Chinese students of non-English major English vocabulary learning strategies. The Foreign Language Teaching, 78, 46-50.

WANG, Y. Y. (1998) .Vocabulary memory strategies of English major and non-english major students. Foreign Language Teaching and Research, 1, 25-27.

WEN, Q. F. (1996). English learning strategies. Shanghai: Shanghai Foreign Language Education Press.

WEN, Y. W. (1998). An English major and non-English major students' vocabulary memorization strategies. The Foreign Language Teaching and Research, 32, 22-28.

WU, X., \& WANG, Q. (1997). Vocabulary learning strategies of non-english major undergraduate. Foreign Language Teaching and Research, 4, 53-57.

YAN, P. D. (2001). The communicative approach in teaching vocabulary of direct and indirect learning. The Journal of Foreign Language Teaching and Research, 22, 186-192. 